of experience on the subject of tuberculosis of bone and joint. It was fortunate that $\mathrm{Mr}$. Somerville had already been brought in as a co-author, and one hopes that senior writers of other books which grace British surgical literature may follow the example and ensure a measure of continuity of their life work. The new reader must remember that Girdlestone was a doughty campaigner for the modern régime of healthy open-air treatment, and one who never let up; for this reason some of the text reads like persuasive argument, as if the fight, now happily won, were still joined.

This book has no strong competitor in Great Britain, and such is the all-round quality of the teaching of the Oxford school that only a minor point here and there can be selected for mild critical comment. For example, the authors state that a single examination of the sedimentation rate is of little value in the diagnosis of tuberculosis. This remark is hardly fair to the test, because the finding of a raised rate often sounds a note of alarm leading to further investigation and the correct diagnosis. Many cases of early involvement of the spine and shoulder joint, not to mention ankylosing spondylitis, would have been spared manipulative mauling had this very simple test been employed only once. The baneful sideeffects of prolonged and uninterrupted immobilization in recumbency are fully discussed, but it is disappointing to find no reference to the painstaking work of Nangle, a pupil of Girdlestone, on the value of balanced suspension of frames and plaster beds, both for the patients lying on them and for the convenience of the nursing staff.

Perhaps too many rather obvious radiographs are devoted to differential diagnosis; the readers of such a special subject might reasonably be expected to be familiar with the appearance of an advanced Charcot knee, of spondylolisthesis of third degree, and of adolescent coxa vara with slipping of the head of the femur in both views. Incidentally, two of the radiographs of arthrodesis of the hip joint show the femur away out in abduction of about twenty-five degrees, much in excess of the declared ideal of nought to five degrees.

The practising surgeon, looking in vain for detailed advice on his special problem, may conclude that the book could well contain more precise instruction in the same number of pages. For example, a fuller description of the treatment and maltreatment of psoas abscess, and the way to use that essential piece of equipment, the wide-bore aspirating syringe of Gauvain, might replace a couple of the longer case-histories. Perhaps this is the direction the book will take in the years to come under its new and able editor.

K.I.N.

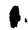

THE ETHICAL BASIS OF MEDICAL PRACTICE

By Willard L. Sperry. Pp. 185 . London: Cassell and Co. 1952. I2s. 6d.

This book fills a void in the education of the young doctor. Ethical standards should be planted in the personality of the child in its own home and nursed during school days. Often however, seeds if present, do not germinate. Hence the need that $\stackrel{\otimes}{\circ}$ this book satisfies.

There are chapters on Medicine and the priest; the specialist and the general practitioner; the nature of conscience, etc. It is when such subjects $\overline{0}$ as euthanasia are discussed that criticism might be $\frac{C}{0}$ called for. Why is euthanasia a medical problem? $\overline{\bar{\omega}}$. Why is this included in the ethical basis of medical $\vec{\sigma}$ practice; as distinct, for instance, from legal $\propto$ practice?

An action which is ethical to a Protestant may $\rightarrow$ be unethical to a Roman Catholic. Eating beef, ethical to both Protestants and Catholics is not so $\vec{\omega}$ to a Hindu. It therefore follows that it is necessary $\stackrel{\sigma}{\sigma}$ for an author and also for an individual to decide 8 his position and to define it if he is to write and 3 live with sincerity and conviction. This book helps is to do this.

The duty of a doctor or a surgeon is to restore the human being to as near bodily perfection as possible and to relieve pain and anguish. Do many doctors assume other functions? They may get themselves up as judges to decide who should live $ᄋ$ and who should die. To be able to judge, all facts must be revealed. No human mind can ever know all the facts. It will never be possible for a human being to judge and decide whether one should live and another should die. Therefore the question of euthanasia presents no problem to the true doctog Sometimes doctors are tempted to become prophet $\overrightarrow{0}$ They could and should give a prognosis. But as no man can foretell what will happen from one five minutes to the next with certainty, the death sen- o tence should therefore never be pronounced with the conviction of the oracular.

If a man practises as a doctor in true humility his ethical problems are few. Each problem is like a $\stackrel{\mathbb{Q}}{\complement}$ Savile Row tailor-made suit, i.e. it is made for a $\overrightarrow{\vec{P}}$ particular individual at a particular period of time; $\frac{\rho}{3}$ so is each ethical problem. It can only be resolved by the individual in relation to the circumstances at the time he is consulted. If on the other hand, a doctor is arrogant and takes on the function of judge, prophet and executioner the British Museum is not large enough to contain all that might be written on the problems that would arise. Furthermore, these problems are not problems of medical ethics but general ethical problems.

This book discusses these matters seen through 우 the spectacles of the Dean of Divinity at Harvard. Most helpful guidance is given in all these matters.

MEDICAL HISTORY OF THE SECOND . WORLD WAR

\section{Medicine and Pathology}

Edited by V. ZACHARY COPE, B.A. M D M S F.R.C.S. Pp. xxix + 565. London: H.M.S.O. I 952.50 .

The 'Medical History of the Second World $\stackrel{?}{?}$ War' is planned to consist of 18 volumes. Of 7 these, the first to appear is 'Medicine and Path- 